\title{
Christian Sorrel (éd.), Les carnets de François Molin. Un prêtre dans la tourmente (1792-1802)
}

\section{Caroline Chopelin-Blanc}

\section{(2) OpenEdition \\ 1 Journals}

\section{Édition électronique}

URL : https://journals.openedition.org/ahrf/10652

DOI : 10.4000/ahrf.10652

ISSN : 1952-403X

Éditeur :

Armand Colin, Société des études robespierristes

\section{Édition imprimée}

Date de publication : 1 avril 2009

Pagination : 221-222

ISBN : 978-2-200-92558-1

ISSN : 0003-4436

\section{Référence électronique}

Caroline Chopelin-Blanc, « Christian Sorrel (éd.), Les carnets de François Molin. Un prêtre dans la tourmente (1792-1802) », Annales historiques de la Révolution française [En ligne], 356 | avril-juin 2009, mis en ligne le 17 décembre 2009, consulté le 23 avril 2022. URL : http://journals.openedition.org/ ahrf/10652 ; DOI : https://doi.org/10.4000/ahrf.10652

Ce document a été généré automatiquement le 23 avril 2022.

Tous droits réservés 


\title{
Christian Sorrel (éd.), Les carnets de François Molin. Un prêtre dans la tourmente (1792-1802)
}

\author{
Caroline Chopelin-Blanc
}

\section{RÉFÉRENCE}

Christian SORREL (éd.), Les carnets de François Molin. Un prêtre dans la tourmente (1792-1802),Montmélian, La Fontaine de Siloé, Coll. Carnets de vie, 2008, 382 p., ISBN 978-2-84206-418-1, $19 €$.

1 Christian Sorrel a entrepris l'édition des notes prises pendant la Révolution et le début $\mathrm{du}$ Consulat, par un certain François Molin, prêtre réfractaire savoyard, qui exerçait son ministère dans la vallée de la Maurienne. Le manuscrit original, longtemps conservé au presbytère d'Epierre, paroisse de la basse vallée de l'Arc, et désormais déposé aux archives diocésaines de Maurienne, a été édité une première fois en 1868 , mais de façon incomplète. Christian Sorrel a pris soin de reproduire l'intégralité du texte, en modernisant l'orthographe et la ponctuation. Les « carnets » concernent la période 1793-1802, mais relèvent en fait de deux modes de conception bien différents. Le récit des années 17931798, élaboré en 1798 à partir de notes prises dès 1793, s'apparente à des mémoires: les résumés, les bilans, les anticipations, ainsi que certaines erreurs chronologiques, révèlent une écriture postérieure. Pour la période 1799-1802, il s'agit plutôt d'un journal : l'abbé Molin livre un récit très détaillé, quasi quotidien, de ses faits et gestes, lequel constitue près de la moitié de ses carnets. Né à Lanslebourg en 1752, issu d'une famille de cultivateurs de condition moyenne, l'auteur devient curé d'Epierre en janvier 1781. Refusant le serment après la conquête française, il est contraint de se réfugier dans le Piémont en février 1793. Après plus de deux ans d'exil, il revient dans sa vallée au printemps 1795 et, à partir d'Epierre, rayonne dans les paroisses voisines, vivant la plupart du temps dans la clandestinité. Le 17 mai 1802, il cesse de rédiger son journal, non en raison d'une incapacité (il reste curé de sa 
paroisse jusqu'à sa mort 33 ans plus tard, en 1835), mais parce que la mise en place du régime concordataire et la restauration de la paix religieuse ne justifient plus à ses yeux le recours à l'écriture.

2 Afin de faciliter la lecture, Christian Sorrel a pris le parti de sectionner ces "carnets " en quatre chapitres chronologiques clairement distincts: 1793-1795, «le temps de l'exil »; 1795-1797, « les espoirs et les désillusions »; 1797-1799, « la seconde Terreur »; 1799-1802, «le début du Consulat et l'attente de la pacification religieuse ». Des notes très fournies nous renseignent sur le contexte politique national et local, guère évoqué par François Molin, sur les personnages rencontrés, sur les citations bibliques ainsi que sur les allusions liturgiques de l'auteur. Deux cartes, l'une sur l'espace de l'exil et l'autre sur l'espace de la mission, qui prennent en compte les dénivelés de cet espace montagneux, aident de plus à visualiser les déplacements et les différents lieux d'action de François Molin. Enfin, il faut souligner l'extrême utilité de l'index des noms propres.

3 Cette édition intégrale et critique des carnets de ce prêtre réfractaire mauriennais apporte un éclairage de qualité sur l'histoire religieuse de la Révolution et l'histoire de la Savoie en Révolution. Elle aide à saisir les difficultés rencontrées au quotidien par les prêtres réfractaires, à la fois sur les plans matériel, liturgique et institutionnel. Les carnets informent également sur le comportement même des fidèles, leur degré de sacramentalisation, les solidarités mises en œuvre pour protéger leur curé. De surcroît, ce travail éditorial participe à une connaissance plus fine de l'histoire de la Savoie sous la Révolution. Sont notamment abordées les questions de l'attitude des autorités locales face au problème religieux, de l'application nuancée des directives du pouvoir central ainsi que du rôle stratégique d'une grande vallée alpine entre France et Italie. Néanmoins, on peut déplorer l'absence d'index topographique et le manque de netteté de certains documents iconographiques, comme les deux reproductions du cadastre sarde p. 134 et p. 158 . Ces quelques remarques ne pèsent toutefois que très peu au regard de la qualité de cette édition. Christian Sorrel met à la disposition de tout lecteur curieux d'histoire révolutionnaire, d'histoire religieuse ou d'histoire locale, un témoignage, richement commenté et agréablement présenté, d'un prêtre réfractaire « ordinaire ». 